$\frac{\text { PNL-10165 }}{\text { UC-900 }}$

Final Project Report

\title{
Technology Maturation Project on Optimization of Sheet Metal Forming of Aluminum for Use in Transportation Systems
}

K. I. Johnson

M. T. Smith

C. A. Lavender

M. A. Khaleel

October 1994

Prepared for the U.S. Department of Energy under Contract DE-AC06-76RLO 1830

Pacific Northwest Laboratory

Operated for the U.S. Department of Energy

by Battelle Memorial Institute 


\title{
DISCLAIMER
}

This report was prepared as an account of work sponsored by an agency of the United States Government. Neither the United States Government nor any agency thereof, nor Battelle Memorial Institute, nor any of their employees, makes any warranty, expressed or implied, or assumes any legal liability or responsibility for the accuracy, completeness, or usefulness of any information, apparatus, product, or process disclosed, or represents that its use would not infringe privately owned rights. Reference herein to any specific commercial product, process, or service by trade name, trademark, manufacturer, or otherwise does not necessarily constitute or imply its endorsement, recommendation, or favoring by the United States Government or any agency thereof, or Battelle Memorial Institute. The views and opinions of authors expressed herein do not necessarily state or reflect those of the United States Government or any agency thereof.

\author{
PACIFIC NORTHWEST LABORATORY \\ operated by \\ BATTELLE MEMORIAL INSTITUTE \\ for the \\ UNITED STATES DEPARTMENT OF ENERGY \\ under Contract DE-AC06-76RLO 1830
}

Printed in the United States of America

Available to DOE and DOE contractors from the

Office of Scientific and Technical Information, P.O. Box 62, Oak Ridge, TN 37831; prices available from (615) 576-8401. FTS 626-8401.

Available to the public from the National Technical Information Service, U.S. Department of Commerce, 5285 Port Royal Rd., Springfield, VA 22161. 


\section{Final Project Report}

\section{Technology Maturation Project on Optimization of Sheet Metal Forming of Aluminum for Use in Transportation Systems}

Ken I. Johnson Mark T. Smith Curt A. Lavender Mohammad A. Khaleel

October 1994

Prepared for U.S. Department of Energy under Contract DE-AC06-76RLO 1830

Pacific Northwest Laboratory

Richland, Washington 99352 


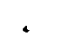




\section{Technology Maturation Project on Optimization of Sheet Metal Forming of Aluminum for Use in Transportation Systems}

Staff exchanges are intended to facilitate communication and collaboration among scientists and engineers at Department of Energy (DOE) laboratories, in U.S. industry, and academia. The exchanges offer the opportunity for the laboratories to transfer technology and expertise to industry, gain a perspective on industry's problems, and develop the basis for further cooperative efforts through Cooperative Research and Development Agreements (CRADAs) or other mechanisms such as this technology maturation project.

\section{Background}

Using aluminum instead of steel in transportation systems could dramatically reduce the weight of vehicles-an effective way of decreasing energy consumption and emissions. Researchers at the Pacific Northwest Laboratory (PNL) have teamed with an industry partner, an aluminum supplier, and university researchers (Washington State University and the University of Michigan) to develop and optimize sheet metal forming of aluminum for the automotive industry. Sheet metal forming (SMF) of aluminum allows light, complex structures to be formed through a single-step process. The increased formability of SMF over conventional methods can also reduce the number of parts and assembly operations required.

Superplastic forming has been used for over 20 years in the aerospace industry to produce very complex shapes. In Europe, superplastic formed aluminum has replaced plastic and fiberglass panels in subways and commuter trains to reduce the potential for toxic fumes in the event of a fire. In aircraft, superplastic forming of titanium has been coupled with diffusion bonding and welding to produce multisheet, stiffened structures that are stronger, lighter, and less expensive than the assembly they replace.

Superplasticity in metals is defined by very high tensile elongations, ranging from two hundred to several thousand percent. The process, conducted under controlled temperature and strain rate, can give a tenfold increase in elongation compared to conventional sheet stamping processes. Aluminum alloys with sufficient strength for vehicle applications do not have the ductility of steel at room temperature and therefore cannot be directly substituted in conventional manufacturing. Superplastic forming provides a method of producing components with the same structural performance and reduced weight.

The current cost of SMF aluminum alloys (about $\$ 4$ per pound) and the relatively long forming times (several minutes to several hours) of current materials are serious drawbacks to the widespread use of SMF in industry. Although the current state of SMF technology is applicable to high value, limited production components (such as many aerospace applications), forming times must be reduced and lower cost SMF alloys must be developed for this technology to be usable in the automotive industry.

The interdependence of materials testing and model development is critical to optimizing SMF since the current process is conducted in a heated, pressurized die where direct measurement of critical 
SMF parameters is extremely difficult. Numerical models provide a means of tracking the forming process, allowing the applied gas pressure to be adjusted to maintain the optimum SMF behavior throughout the forming process. Thus, models can help produce the optimum SMF component in the least amount of time.

\section{Purpose/Objective}

The Pacific Northwest Laboratory is integrating SMF model development with research in improved aluminum alloys for SMF. The objectives of this research are

- develop and characterize competitively priced aluminum alloys for SMF applications in industry

- improve numerical models to accurately predict the optimum forming cycle for reduced forming time and improved quality

- verify alloy performance and model accuracy with forming tests conducted in PNL's Superplastic Forming User Facility.

The activities performed in this technology maturation project represent a critical first step in achieving these objectives through cooperative research among industry, PNL, and universities.

\section{Summary of Activities Performed}

\section{Alloy Characterization}

With Energy Research, Laboratory Technology Transfer Program (ER-LTT) funding support, researchers at the University of Michigan began an evaluation of the superplasticity in two modified 5083 aluminum alloys. To date, the research has focused on the development of fine grain sizes in one of the alloys by thermomechanical treatments. By manipulating the microstructure of the alloy, $U$ of $M$ has begun to understand the role of the precipitates in the microstructural evolution. In addition, $\mathrm{U}$ of $\mathrm{M}$ has initiated studies for the development of constitutive relations for SMF of 5083 alloys. Recent research indicates that current models based on grain growth will not adequately predict the behavior of 5083 aluminum-based alloys. Additional terms which account for deformation strengthening and dynamic recovery will be required.

\section{Model Testing and Development}

Early work by PNL focused on investigating existing finite element codes for their capabilities in simulating the superplastic forming process. This effort identified the MARC finite element code as having the most advanced capabilities for this type of analysis. Additional factors that supported the use of MARC were 1) the ongoing interest of the MARC code developers in continuing to improve the SMF capabilities, and 2) the ability to directly link user defined material models and solution control algorithms to the MARC solution procedure. 
Two test simulations were initially completed to demonstrate the SMF capabilities of the MARC code. The results of this modeling effort were presented during a program review for an industry partner on October 14-15, 1992. First, a two-dimensional model was constructed to simulate forming of a stiffening rib in an electric vehicle battery tray (Figure 1 in Appendix A). This component had been produced by PNL and Boeing using the SMF process. Team members attending this meeting presented a cross-sectioned slice of the battery tray rib that confirmed the general thinning predictions given by the MARC code. Second, a three-dimensional model was constructed to simulate forming of a multisheet, stiffened panel that had also been manufactured by Boeing (Figure 2 in Appendix A). The three-dimensional multisheet simulation was particularly significant since this demonstrated that MARC had advanced three-dimensional sheet forming and contact capabilities that allowed simulating multisheet SMF. To our knowledge, these combined capabilities had not been successfully demonstrated on a three-dimensional, multisheet SMF problem by any other commercially available code.

In addition to providing the staff time for code evaluation and model development, ER-LTT funds have also supported our ongoing license agreement for the MARC finite element code. This has allowed uninterrupted access to the MARC software while continuing the modeling effort to better correlate model results with SMF forming tests.

\section{Model Verification with Forming Tests}

The primary objective of modeling the SMF process is to predict a pressure-time history that will produce a quality part in the least amount of time. Therefore, it is important to verify that models can predict what will occur in the actual forming process. A finite element model was developed to simulate forming of a long, deep rectangular box known as the "butter-tray." This geometry was chosen for forming experiments in PNL's pilot scale SMF press because it provides a plane-strain section in the center of the box and an area of high strains (300 to $400 \%$ engineering strain) in the corners. Models were constructed and run of a $1 / 4$ symmetry section of the box (Figure 3 in Appendix A). However, the run-times were excessive ( 80 hours on a Sun SPARC-10 computer) using the elastic/plastic formulation with shell elements. In response to our experience and comments, the development staff at MARC Analysis made improvements in their rigid/plastic flow formulation to make it useful in simulating SMF. The rigid-plastic flow formulation treats the SMF process as a purely rate-dependent plasticity problem. This approach eliminates the need to partition elastic and plastic strains and allows treating the rate-dependent flow stress as a viscous effect. This solution method coupled with the use of membrane elements reduced the run time of the "butter-tray" model by more than a factor of ten.

The comparisons between model results and forming tests have taken on a dual focus: 1) to implement alloy-specific test data into the material constitutive model and 2) to improve the solution control algorithm to better track the optimum strain-rate throughout the forming cycle. A user subroutine was written to account for the strain and strain-rate variation in flow stress and it allows for input of material test data in tabular form. The routine also tracks strain and strain-rate and controls the applied pressure to maintain the optimum strain rate. This is accomplished in each solution increment by sorting to find the maximum strain-rate and the corresponding flow stress in the model. The target flow stress is calculated for the current strain and the target strain-rate. This value is compared to the 
actual flow stress and the applied pressure is adjusted by the ratio of these stresses. This algorithm controls the strain-rate throughout the simulation.

Although many improvements have been made in modeling SMF using the MARC code, additional work remains in improving the correlations between model predictions and the results of forming test. Pressure-time histories generated to date by the models have produced acceptable parts, however, partial forming experiments (i.e., the tray was not formed to completion) show differences in the partially formed geometry. This is thought to be due to differences in the die-to-sheet friction and in actual material behavior compared with that simulated by the model. These differences are being addressed in the ongoing work.

\section{Significant Accomplishments}

\section{Demonstration of Integrated Approach to Optimizing SMF}

Throughout our discussions with an industry parnter it was stressed that optimization of SMF would require 1) alloy development, 2) material characterization and numerical model development, and 3) verification of alloy performance and model accuracy through forming tests. This multiphase emphasis coupled with the select team of industry (Kaiser Aluminum and MARC Analysis) and university (WSU and $U$ of $M$ ) participants has given the industry partner confidence in the potential for success from this work.

\section{Participation in DOE Sponsored Aluminum Forming Workshop}

During May 3-5, 1993, Mark Smith, Curt Lavender, and Ken Johnson attended the DOEsponsored, ASME workshop on "Research Guidelines for Aluminum Products Application in Transportation and Industry" in Clearwater Beach, Florida. Mark Smith's presentation, "Optimization of the Superplastic Behavior of 5XXX Aluminum Alloys," (presented in Appendix B) described the results of work in thermal mechanical processing and characterization of aluminum alloy 5083. Ken Johnson's presentation, "Numerical Models for Optimizing Superplastic Forming of Aluminum," (presented in Appendix C) described the results of the SMF modeling effort. Both presentations were well received and several people commented on the timely and practical nature of the SMF research that PNL is performing.

\section{SPF CRADA Awarded by DOE ER}

Based on the results of this project, a spinoff CRADA proposal regarding the modeling and simulation of SMF was developed. The purpose of the CRADA was to initiate formal collaborative research with an industry partner, MARC Analysis Research Corporation, and university researchers to develop and enhance the modeling and simulation capabilities for sheet metal forming. The proposal identified two tasks: 1) development of material constitutive models and 2) development of predictive SMF codes. This proposal was accepted by DOE ER and work began in March 1994. 


\section{Significant Problems}

None

\section{Industry Benefits Realized}

The industry partner has realized significant initial progress in efforts to transfer SMF technology for application by the vehicle manufacturing industry. MARC Analysis has obtained significant improvements in its finite element code for SMF. These improvements have the potential to benefit other U.S. industries that utilize SMF technology, such as the aircraft manufacturing industry.

\section{Recommended Follow-On Work}

Follow-on work is being conducted under the previously mentioned CRADA funded by ER-LTT. The modeling and simulation work conducted under the CRADA will be coupled with experimental work on SMF technology sponsored by the National Aeronautics and Space Administration and the DOE Office of Energy Efficiency and Renewable Energy.

\section{Potential Benefits from Pursuing Follow-On Work}

The development of enhanced SMF modeling and simulations capabilities will allow U.S. industry to design and produce a higher-volume of superplastically formed structures and components than is currently being produced. The elimination of costly, time-consuming, trial-and-error development of tooling designs and forming operations will reduce costs and shorten product development cycles for industry. Efficient modeling and simulation capabilities will allow industry to design components with significantly reduced part count, lower material usage, and improved performance characteristics. 


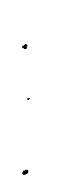


Appendix A

Examples of SMF Models Developed in this Project 

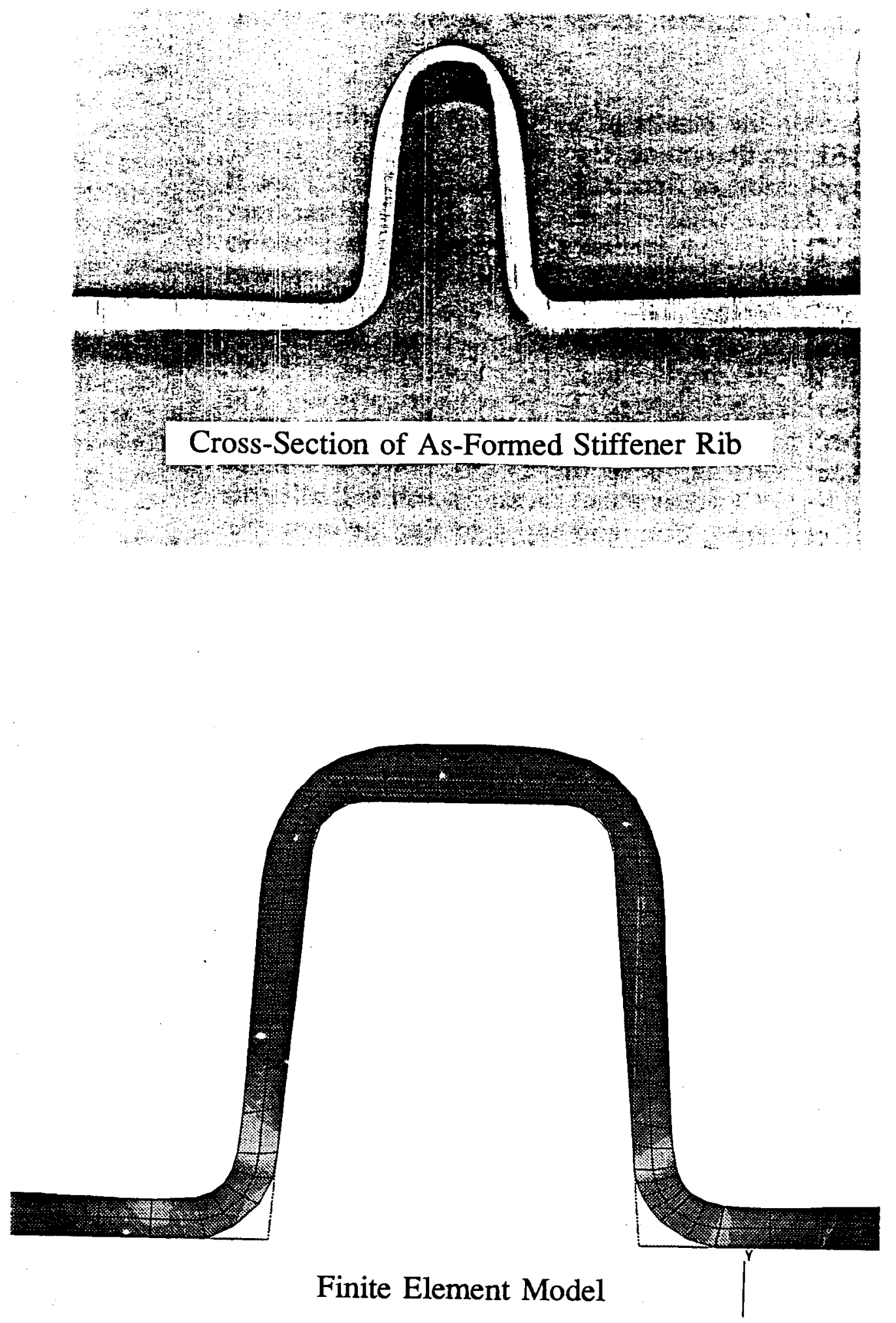

Figure 1. 2-Dimensional SMF Model of Forming Electric Vehicle Battery Tray Rib

A. 1 

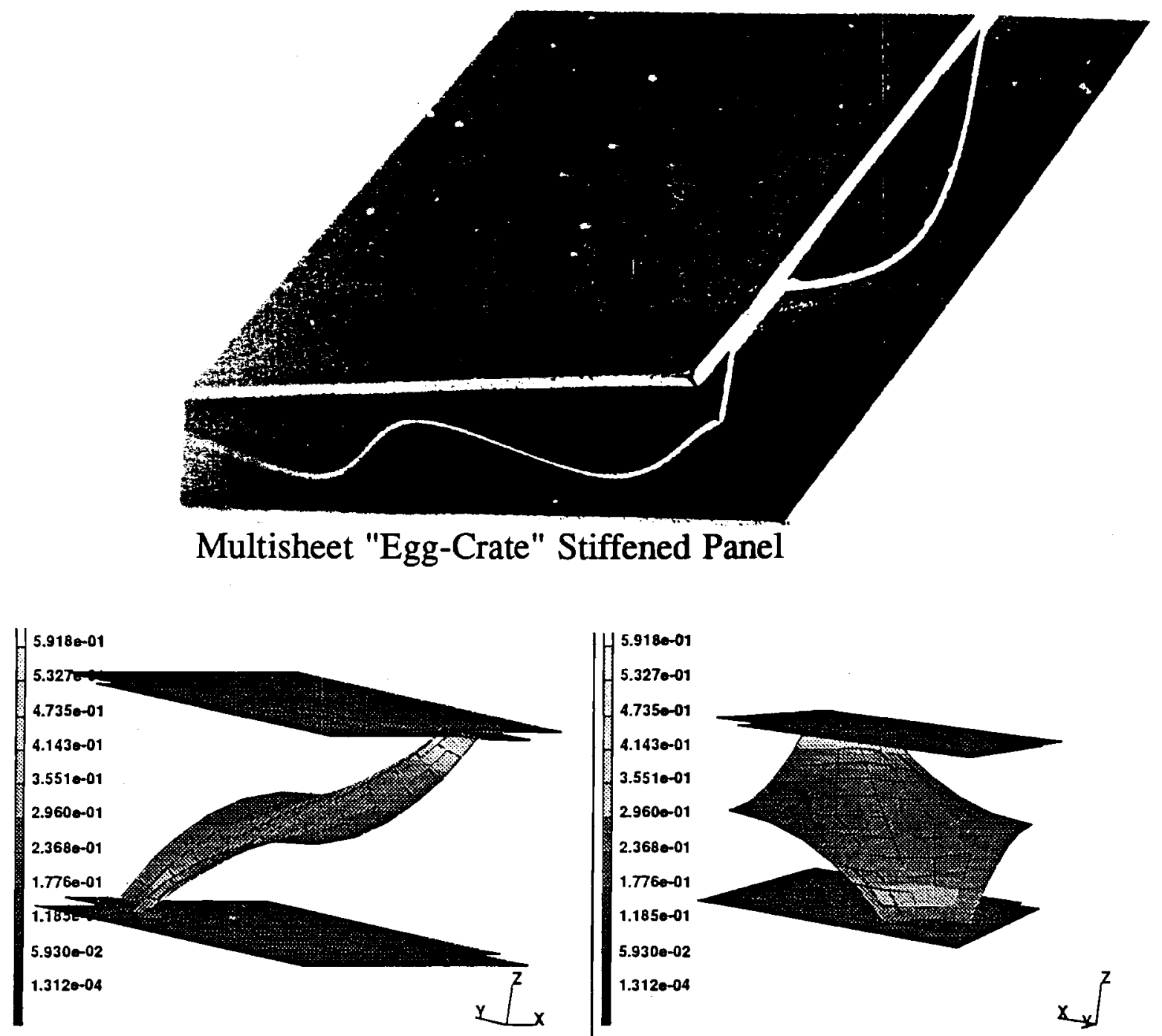

Job1
Equivalent Total Plastic Strain
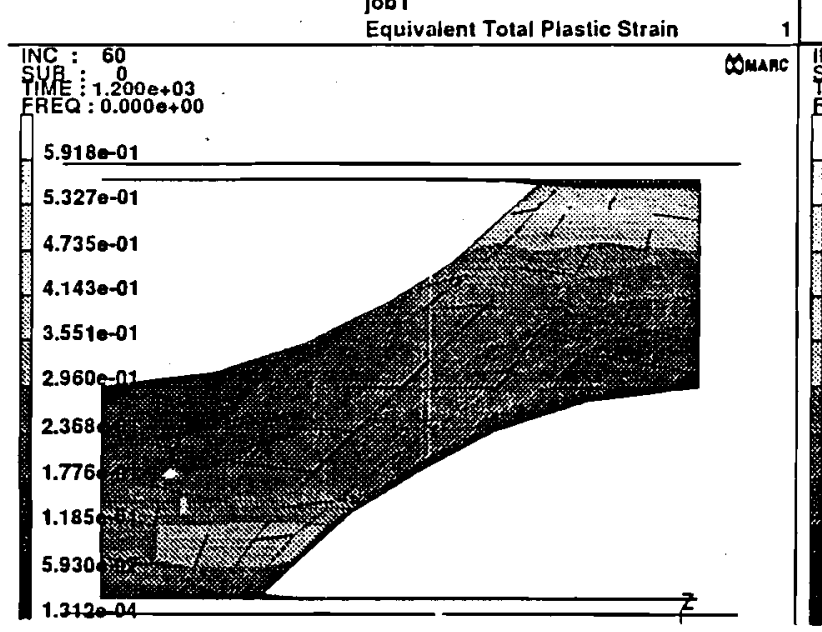

$1.3120-04$

Finite Element Model

Figure 2. 3-Dimensional SMF Model of Forming Multisheet Stiffened Panel 


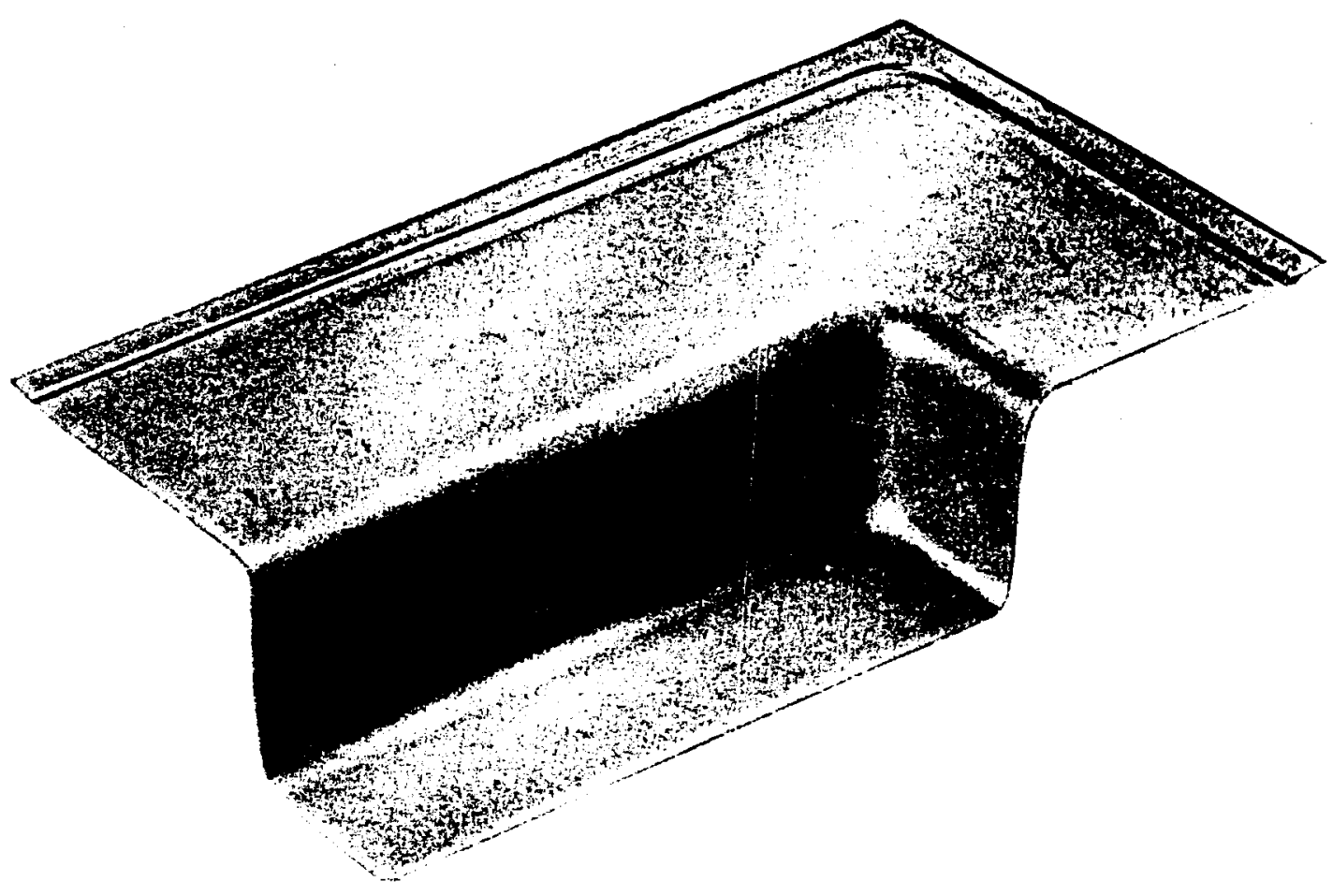

Quarter-Section of Butter-Tray

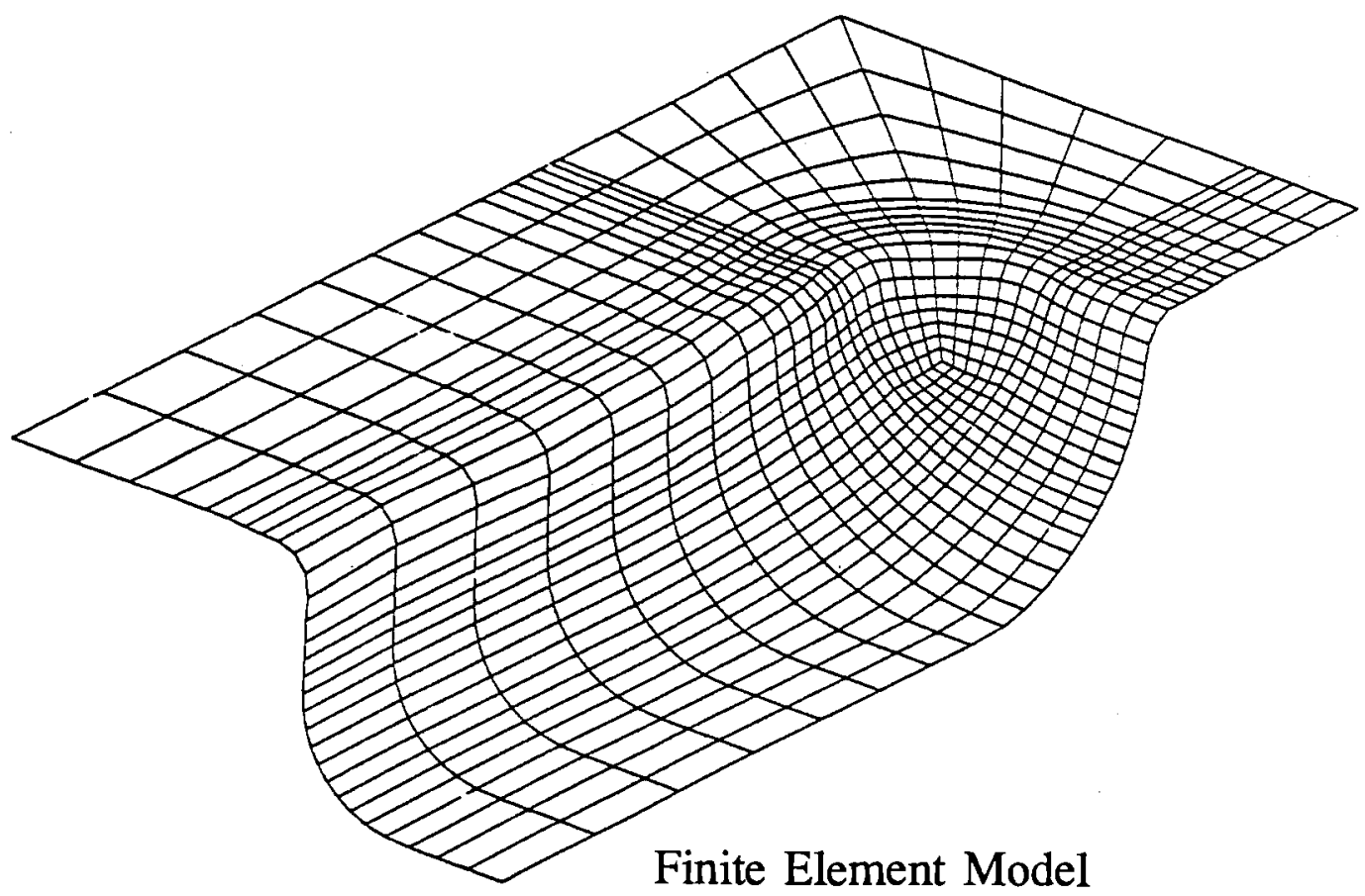

Figure 3. 3-Dimensional SMF Model of Butter-Tray Forming Test 



\section{Appendix B}

\section{Optimization of the Superplastic Behavior of 5XXX Aluminum Alloys}




\section{Optimization of the Superplastic Behavior of $5 X X X$ Aluminum Alloys}

M. T. Smith and C. A. Lavender 
Issues Associated With The Use Of Aluminum in Transportation

- Cost

- Aluminum $\$ 1.60 / \mathrm{lb} ;$ Steel $\$ 0.40 / \mathrm{lb}$

- Formability

- Al does not stamp like steel

- Fastening/Joining

- Requires more preparation

- Corrosion Resistance

- High strength alloys do not meet ground vehicle requirements

- Strength

- High strength desirable without sacrificing above 


\section{Areas for $R \& D$ in Aluminum Fabrication}

- Cold Forming Aluminum Alloys

- High Cost Tooling

- Simple Part Geometries

- Easy Processing

- Superplastic Forming

- Low Cost Tooling

- Intricate Part Geometries; Part Count Reduction

- High Temperature Processing Difficulties

- Fastening/Joining

- Increased Part Complexity 


\section{Emphasis of Presentation}

- Widespread application of SPF to all transportation modes by increasing production rates 


\section{Superplastic Forming of Aluminum Materials Current Domestic Emphasis:}

- Aerospace Contractors

- 7475, Al-Li, 6061-T6

- High Value Components

- Applications which are not cost driven

- "Hand Made" vehicles

- Long Part Forming Times

- Emphasis on post formed strength

- Corrosion Resistance by Coating

- Fabrication by Riveting and Fastening 


\section{Candidate Aluminum Alloy For Low Cost SPF Processing - 5XXX}

- Available

- Widespread use as sheet metal

- Current Domestic Production Base

- Low Cost

- Relative Low Cost Aluminum Alloy to Produce

- Non Heat Treatable

- Does not require post forming heat treatment to develop optimum properties 


\section{Candidate Aluminum Alloy For Low Cost SPF Processing - 5XXX}

- Weldable

- Corrosion Resistant

- Moderate to Low Strength

- "Off Shore" Production of SPF-grade 5XXX

- 5XXX alloys can be made superplastic 


\section{Current Limitations of SPF Aluminum Alloys}

- Cost

- Alloy Content

- Microstructural Requirements

- Supply/Demand

- Slow Forming Rates

$-4 \times 10^{-4}$ or slower $(100 \%$ elongation takes $30 \mathrm{~min})$

- Availability

- Limited Domestic Production 


\section{Need: A High Forming Rate Low Cost Alloy}

- Current SPF Alloys Sell for $\$ 4$ to 6 per lb

- Conventional alloys $\$ 1.40$ to 1.60 per pound

\section{HOWEVER,}

- Not All costs associated with SPF alloys are \$ per lb.

- Forming Times

Trade off part complexity

- Forming Pressures

Utilization by desingers

- Forming Temperatures

Process Control 


\section{Optimizing the SPF of 5XXX Requires:}

- Reduced Cost of SPF grade Alloy

- Alloy Content

- Microstructural requirement

- Increased Forming Rates

- Increased Strength

All without sacrificing weldability and corrosion resistance 


\section{Cost Issues Related to SPF Alloys}

- Alloy Content

- Current alloys require high purity feed materials $\$ 0.05$ to 0.20 per pound premium on "clean" alloys (less than 0.10 Fe requires special feed stock)

\section{Need:}

- Alloys which are less sensitive to impurities to achieve adequate SPF

- Refinement of Impurities by use alternate casting processes

- Demand to increase to justify "exotic" casting processes such as spray casting 


\section{Cost Issues Related to SPF Alloys}

- Fine Microstructures

- Current alloys are made by high levels of cold reduction to produce finer microstructures

- SPF alloys are sheeted and repassed rather than produced in coil

\section{Need:}

- Alternate TMP

- Utilize current aluminum production facilities

- Demand for SPF aluminum to justify re-facilitization

- Eliminate Cross Rolling 


\section{GOAL}

- Merge high production with aerospace technology

- Determine suitable method for evaluating cost 


\section{Cost Issues Associated With SPF Aluminum Alloys}

\section{Supply and Demand}

- Virtually no production of SPF-grade alloys

- Tonnage of components per year 


\section{Utilization of Forming Pressure}

\section{Forming performed at $0.9 \mathrm{Tm}$}

- Allows sharp radii, steep draft angles

- Long tool life

- Low cost tool materials 


\section{Conclusions}

Optimization of an SPF alloy:

- Not just high ductility and low \$ per lb

- Trade off between:

1. Part Complexity (ductility)

2. Forming Rate

3. Forming Pressure (flow stress)

4. Die Life 


\section{Conclusions}

- Tolerance for Production Environment

- 0.9 Melting Temperature

- Feed Product Form; Coil/Sheet

- Cavitation Resistance over broad range of strain rates 


\section{High Volume Production Considerations}

- Production environment requires tolerance for:

- Strain rate (flat $m$ vs strain rate)

- Temperature; microstructure must be stable

- Material Form

- Coil Stock preffered over sheet; low hardness

- SPF machines must be automated to hold tight process control specifications

- Time, temperature, heat up rate all will be parameters

- Minimum cavitation

- over usable strains 


\section{Appendix C}

Numerical Models for Optimizing Superplastic Forming of Aluminum 


\title{
Numerical Models for Optimizing
}

\section{Superplastic Forming of Aluminum}

\author{
Ken I. Johnson
}

Mohammad A. Khaleel

Theoretical and Applied Mechanics Group 


\section{Objectives of PNL's SPF Research}

Develop and characterize aluminum alloys for increased SPF applications in industry

Improve numerical models to accurately predict optimum forming cycles for reduced forming times and high quality SPF components

Verify alloy performance and model accuracy with forming tests conducted in PNL's SPF User Facility 


\section{SPF Modeling Challenges}

Nonlinear, visco-plastic material behavior

$$
\sigma=\mathrm{f}(\dot{\varepsilon}, \varepsilon, \mathrm{d}, \mathrm{T}, \ldots . .)
$$

Nonlinear boundary constraints

Contact of sheet with die surface

Friction between contacting surfaces

Adaptive solution control: Optimize pressure history Multiple control parameters Emphasize part quality 


\section{Example SPF Modeling Code}

British Aerospace SPF code

Optimized for thin sheet SPF applications

Efficient rigid-plastic flow formulation

Sticking friction assumed

Pressure control of strain rate

Adaptive meshing - mesh enrichment 


\section{Adaptive meshing - Mesh enrichment}
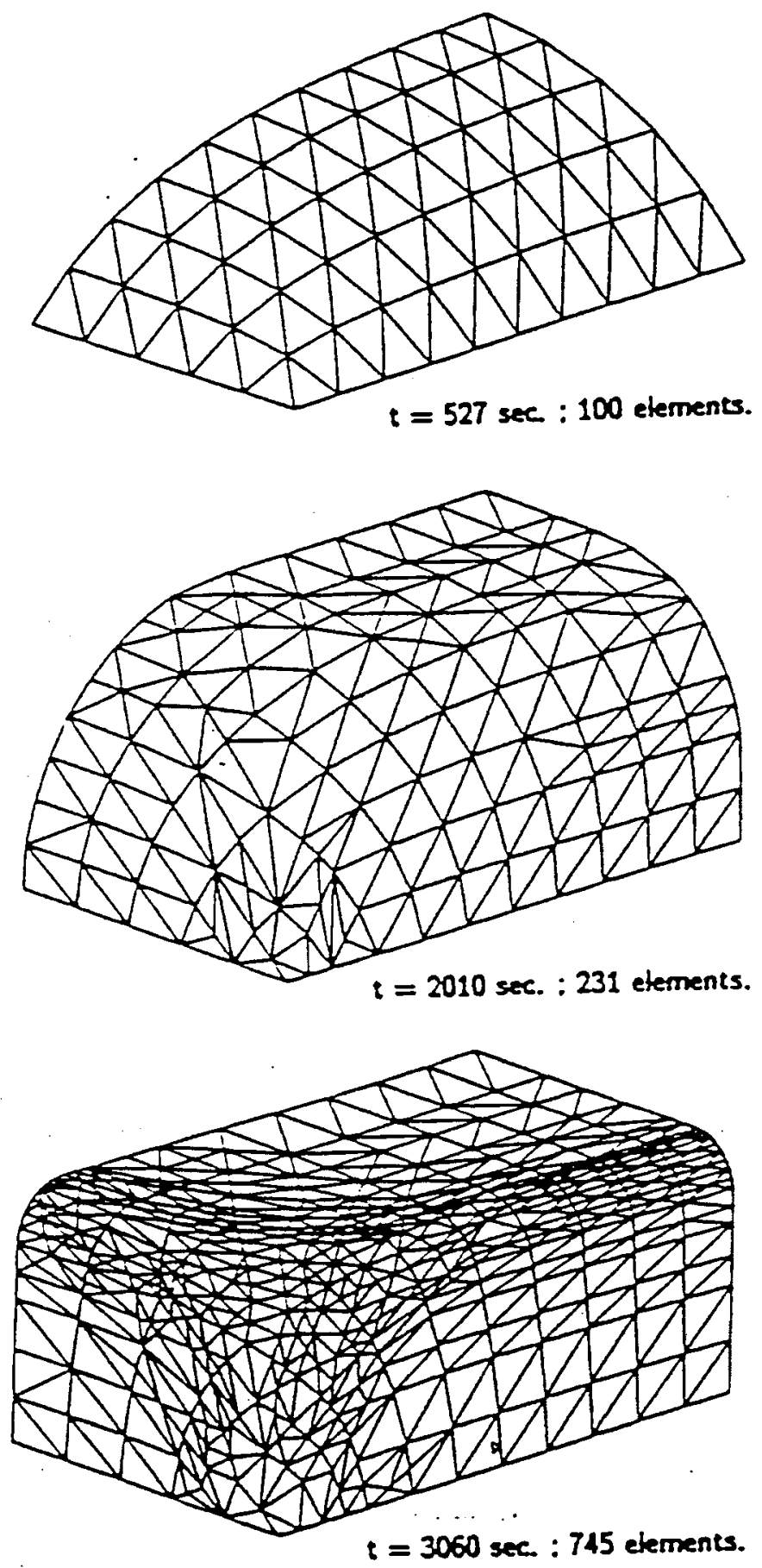

J. BONET, R. D. WOOD AND A. H. S. WARGADIPURA 


\section{Elements of an advanced SPF model}

Accurate material models for aluminum alloys

Accurate and efficient solution methods

Die friction must be better characterized

Improved pressure control algorithms 


\section{Accurate Material Constitutive Models}

Flow stress, $\sigma=\mathrm{f}(\dot{\varepsilon}, \varepsilon, \mathrm{d}, \ldots \ldots$.

Damage - Cavitation and back-pressure effect

- Heat affected zone - Welding

Anisotropy - Uniaxial rolling

- Textural effects from TMP

- Anisotropic yielding, nonassociated flow

- Biaxial testing

Verify with models of uniaxial and biaxial tests 


\section{Characterize Material in Regions I, II, and III}

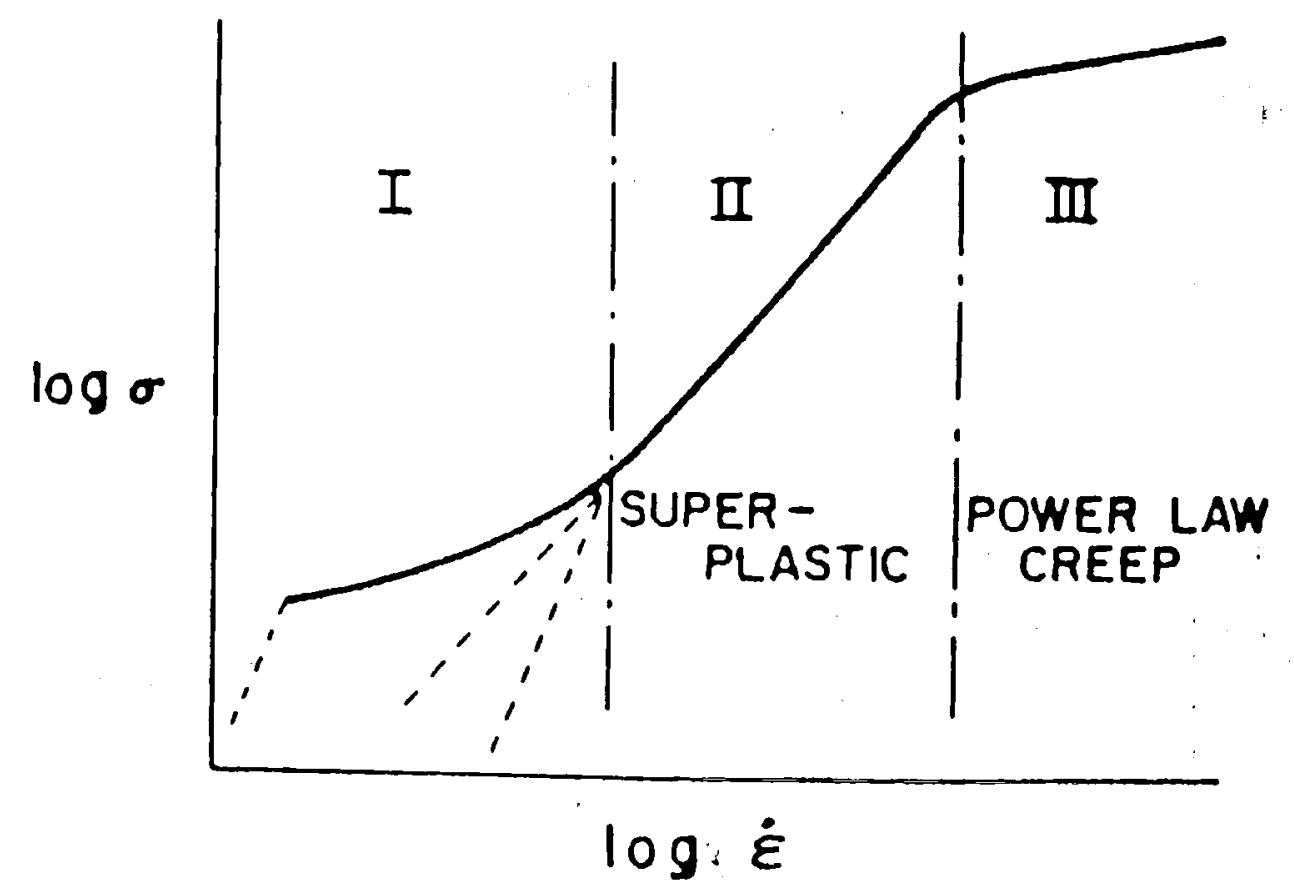




\section{Solution Methods = Accuracy and Efficiency}

Elastic/plastic - Elastic strains included

- Small effect, large time penalty

- Displacement (strain) based

Rigid/plastic - Elastic strains omitted

- Velocity (strain-rate) based

- Efficient

Membrane shell - Thin sheet over large radii

- No bending, 3 DOF's

Shell with bending - Thick sheet forming

$$
\text { - } 6 \text { DOF's }
$$

Reduced integration elements

Adaptive meshing, mesh rezoning

Goal - Solution in time it takes to form part 


\section{$\underline{\text { Die Friction }}$}

Bounding calculations currently used

Frictionless

Sticking friction

Little research to date with regard to SPF

Important factor in model accuracy 


\section{Adaptive Solution Control Algorithms}

Predict pressure history for optimum strain-rate

Variable target strain-rate based on strain

Back-pressure effect on cavitation damage

Press limitations - Maximum forming pressure

- Back-pressure

- Gas flow rate 


\section{PNL using MARC Finite Element Code}

Developed for nonlinear applications (1972)

Numerous solution options

Elastic-visco-plastic

Reduced integration elements

Rigid-Plastic flow formulation

Robust contact algorithms

Open structure via user subroutines

Control algorithms

Material constitutive models

Friction models

Interface with CAE: AutoCad, Ideas, Patran, ProEngineer,IGES

Development Staff interested in SPF 


\section{Verification with Pilot-Scale Forming Tests}

PNL's User Facility and SPF Laboratory

Uniaxial testing

Microstructural evaluation

Murdock SPF Press - 30-inch x 30-inch

Verify alloy performance and model accuracy

Example: "Butter Tray" forming tests 


\section{XXX Series Aluminum}

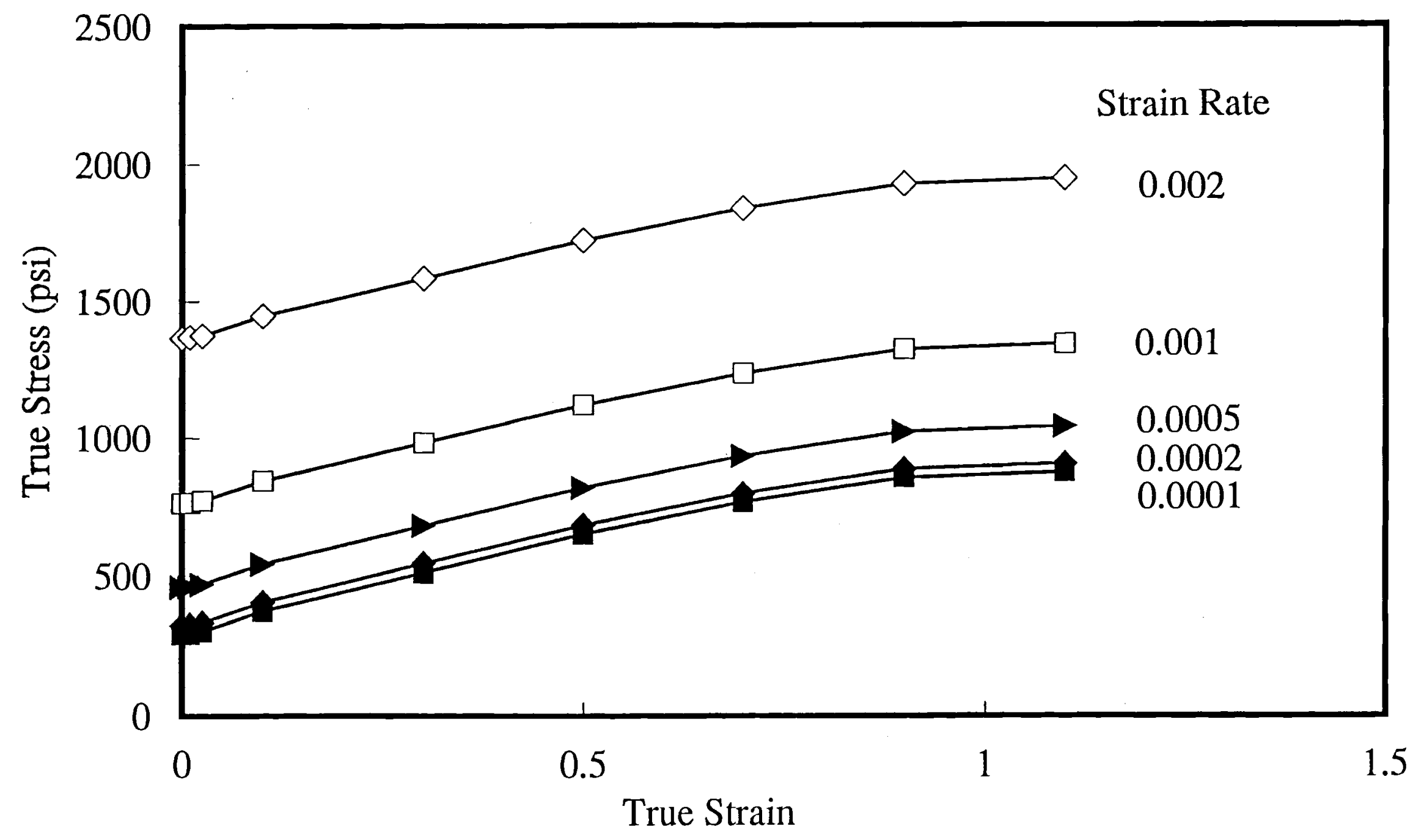




\section{MARC 2-D Butter Tray Model}

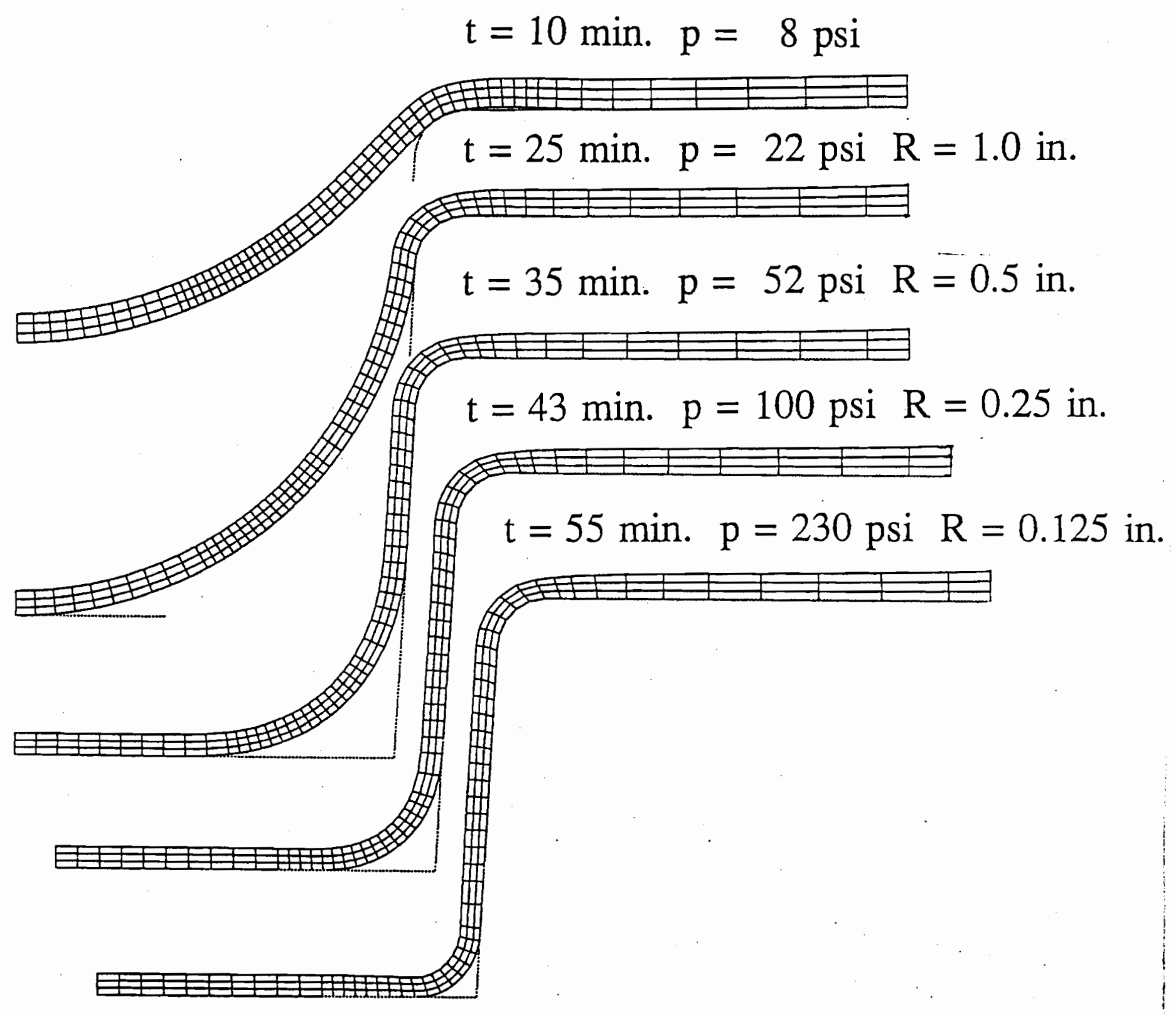




\section{Strain-Rate Variation}

INC : 10

SUB : 0

TIME : $1.2150+02$

FREQ : $0.0000+00$

$7.2010-04$

$6.4840-04$

$5.767 e-04$

$5.049 e-04$

$4.3320-04$

$3.6150-04$
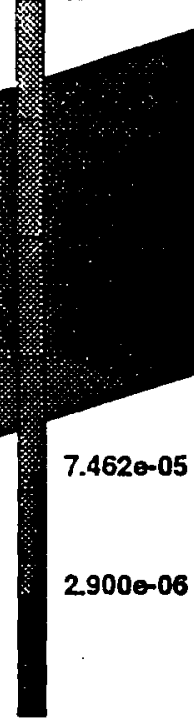

$7.462 \theta-05$

$29000-06$

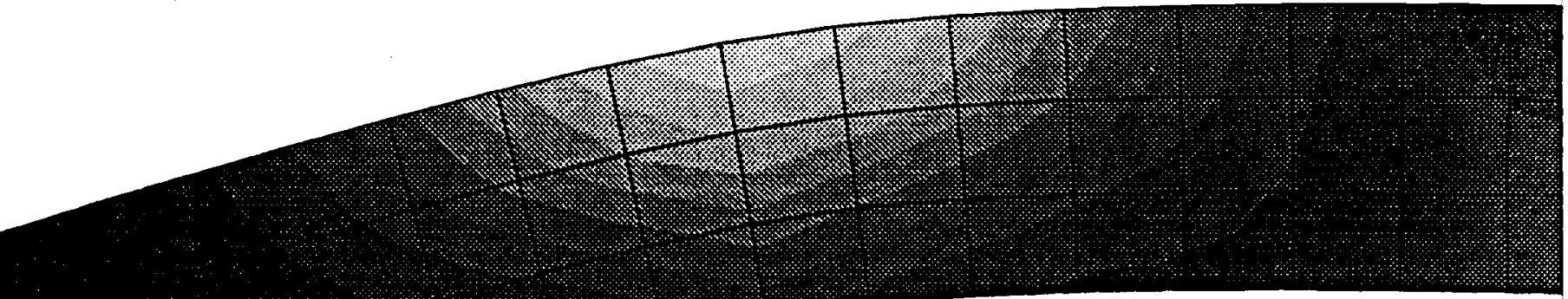




\section{Strain Variation}

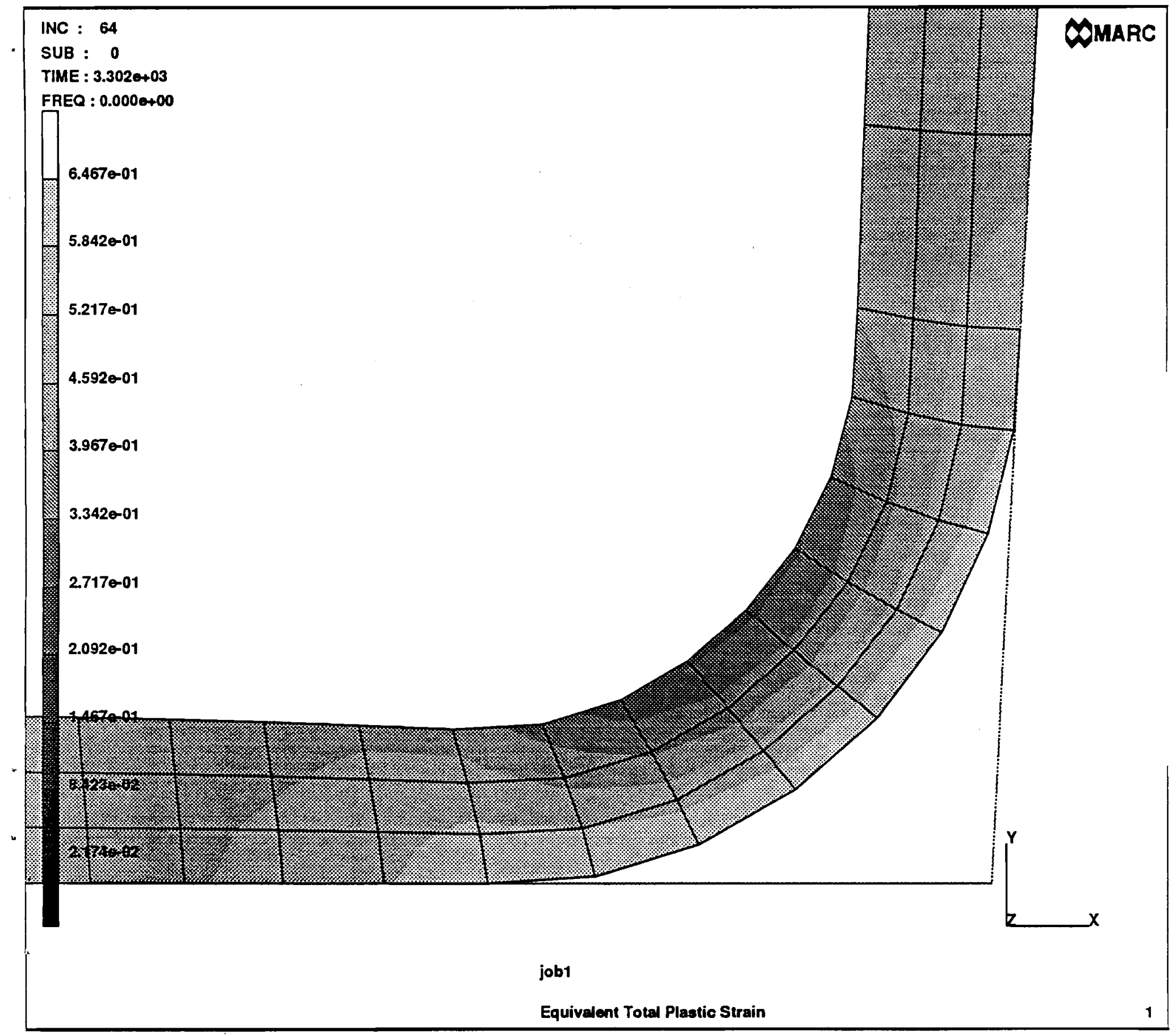




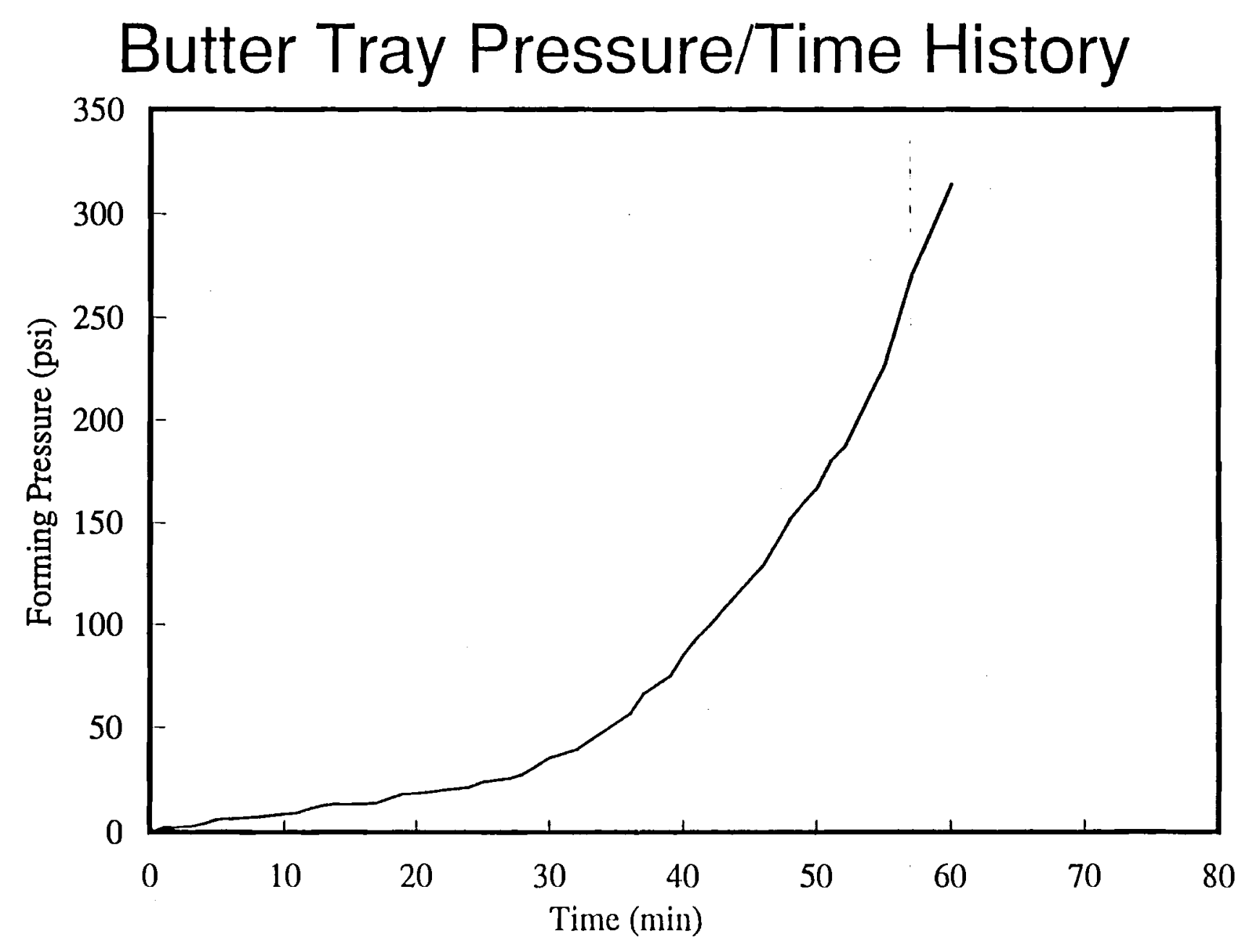

$\stackrel{\Omega}{\infty}$ 


\section{MARC 3-D Butter Tray Model}

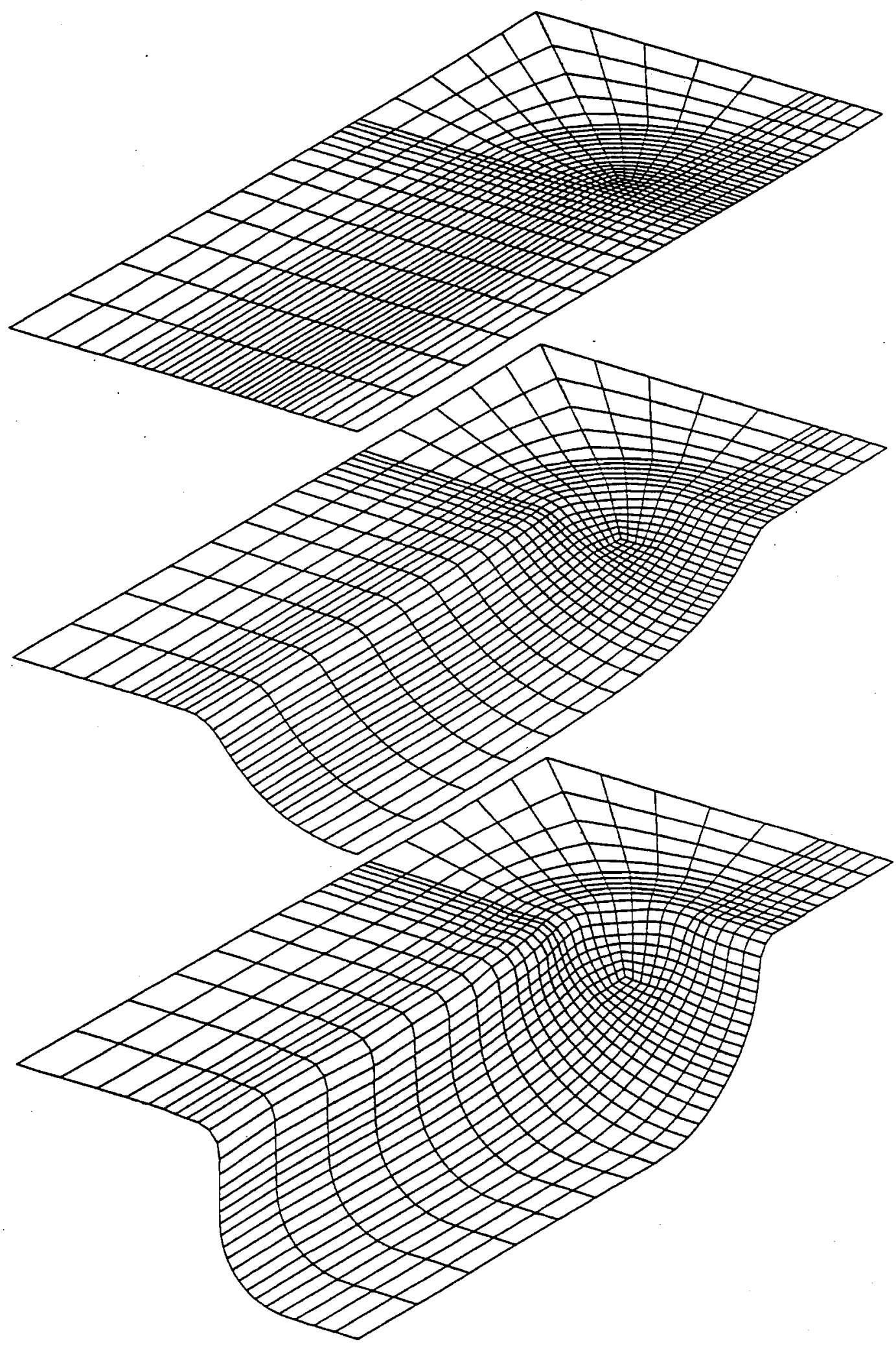




\section{Research Needs for Optimized SPF of Aluminum}

Develop accurate material constitutive models for cost competitive aluminum alloys

Develop accurate and efficient numerical solutions to help optimize forming cycles

Validate numerical models with forming tests 
PNL-10165

UC-900

\section{Distribution}

No. of

Copies

OFFSITE

2 DOE Office of Scientific and Technical Information

M. Abbot

Laboratory Management Division

U.S. Department of Energy

Office of Energy Research

Forrestal Building (ST-311)

1000 Independence Avenue, SW

Washington, D.C. 20585

T. Vojnovich

Technical Program Manager

ER Laboratory Technology Transfer

Program

U.S. Department of Energy

Office of Energy Research

Forrestal Building (ST-311)

1000 Independence Avenue, SW

Washington, D.C. 20585

\section{A. Zerega}

Laboratory Management Division

U.S. Department of Energy

Office of Energy Research

Forrestal Building (ST-311)

1000 Independence Avenue, SW

Washington, D.C. 20585
No. of

Copies

ONSITE

DOE/Richland Operations Office

G. M. McClure

$\mathrm{K} 8-50$

16 Pacific Northwest Laboratory

M. Clement

K1-17

B. J. Harrer (5)

K1-12

K. I. Johnson

K5-22

M. T. Smith (3)

P8-35

Technical Report Files (5)

Distr.1 
